\title{
Human Health Risk Assessment on Drinking Water Safety in Rural area of Ya'an
}

\author{
Fu-quan $N I^{1,2}$ \\ ${ }^{1}$ College of Water resources \& hydropower, \\ Sichuan University. Chengdu, Sichuan Provice, \\ 610091, China. ${ }^{2}$ College of Information \& \\ Engineering, Sichuan Agricultural University. \\ Ya'an, Sichuan Province, 625014, China \\ nfq1965@163.com \\ Shang-chuan $Y A N G^{2,3}$ \\ ${ }^{2}$ College of Information \& Engineering, Sichuan \\ Agricultural University. Ya'an, Sichuan Province, \\ 625014, China. ${ }^{3}$ College of Civil Engineering, \\ Hohai University. Nanjing, Jiangsu Province, \\ 210098, China
}

Abstract-This paper applied the health risk assessment model recommended by the American Environmental Protection Bureau (EPA) , calculation the health risk and analysis the test index about $\mathrm{As}, \mathrm{Hg}, \mathrm{Cr}^{6+}, \mathrm{Pb}, \mathrm{Cd}, \mathrm{F}$ in Ya'an rural drinking water. The result indicates that the average concentration of the pollutants are respectively as follows: As: $0.004 \mathrm{mg} / \mathrm{l}, \mathrm{Hg}$ : $\quad 0.001 \mathrm{mg} / \mathrm{l}, \mathrm{Cr}^{6+}$ : 0.005 0.015 mg/l, Pb: 0.01 mg/l, Cd: $0.005 \mathrm{mg} / \mathrm{l}, \mathrm{F}$ : $0.01 \sim 1.4 \mathrm{mg} / \mathrm{l}$. Among the non-carcinogenic health risk in the research areas caused by the drinking water, the Pb's risk is the biggest, followed by $\mathrm{F}$ and $\mathrm{Hg}$ which risk level is $10^{-8} / \mathrm{a} \sim 10^{-10} / \mathrm{a}$; the carcinogenic risk caused by $\mathrm{Cr}^{6+}$ is the biggest, reaching $10^{-4} / \mathrm{a}$, and meets the EPA requirement, but is higher than the maximal risk level that International Commission on Radiological Protection (ICRP) can accept.

The study is financed jointly by Sichuan Agricultural University Youth Science and Technology Innovation Fund (00530300) and Sichuan Agricultural University Introduces the Talented Person Fund (00530301).

\author{
Guo-dong $L_{I U}{ }^{1}$ \\ ${ }^{1}$ College of Water resources \& hydropower, \\ Sichuan University.Chengdu, Sichuan Provice, \\ 610091, China \\ Xiu-yuan $L U^{2}$ \\ ${ }^{2}$ College of Information \& Engineering, Sichuan \\ Agricultural University. Ya'an, Sichuan Province, \\ 625014, China. \\ Min $Y A N G^{2}$ \\ ${ }^{2}$ College of Information \& Engineering, Sichuan \\ Agricultural University. Ya'an, Sichuan Province, \\ 625014, China.
}

Key words-Ya'an; Rural drinking water safety; Health risk; Calculation and analysis

\section{INTRODUCTION}

The water quality risk is the primary risk of the health risk of the rural drinking water safety in Ya'an. Because the emission of the industrial waste and urban sewage is the primary cause which affects the Ya'an rural drinking water quality, the basic data and the scientific basis for the protection of Ya'an rural drinking water source are provided by gathering and analyzing the samples, and using health risk evaluation model to evaluate the water environment quality.

\section{MATERIAL AND METHOD}

\section{A. Samples Investigation}

The sampling sites of water quality in Ya'an can be seen in Fig. 1. 


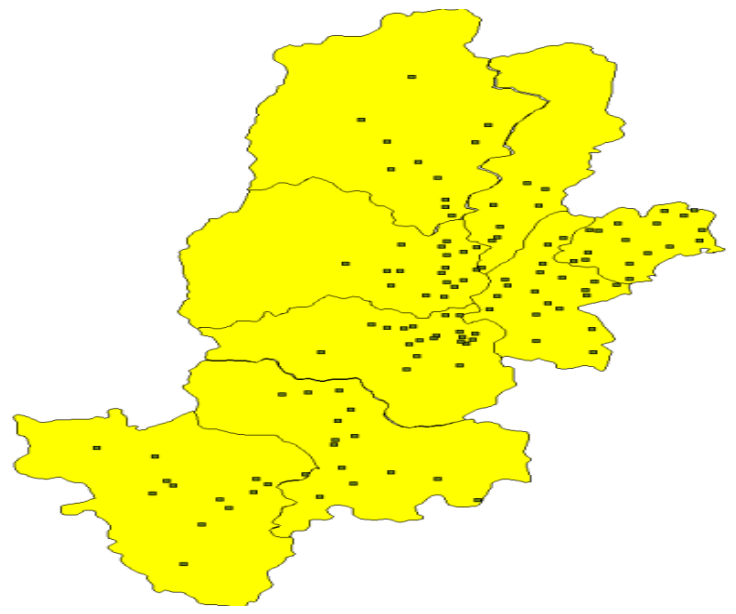

Fig.1 The sampling sites GIS map in Ya'an

\section{B. Evaluation Model}

This paper used the health risk assessment model recommended by the EPA to evaluate the health risk in research area.

\section{RESULTS AND DISCUSSIONS}

\section{A. Water Quality Analysis}

Investigation concentration of rural drinking water source pollutants in Rain City District of Ya'an can be seen in Table 1.

In this district, the pollutants concentration scopes of the water samples are respectively as follows: As: $0.004 \mathrm{mg} / 1, \mathrm{Hg}: 0.001 \mathrm{mg} / 1, \mathrm{Cr}^{6+}$ : 0.005 0.015 mg/l, Pb: $0.01 \mathrm{mg} / \mathrm{l}, \mathrm{Cd}: 0.005 \mathrm{mg} / \mathrm{l}, \mathrm{F}$ : $0.01 \sim 1.4 \mathrm{mg} / \mathrm{l}$. Compared with the Rural Surface Water Environment Quality Standard (GB3838-2002) each indication achieves I III sort of standard except fluoride $(\mathrm{F})$.

TABLE 1. EXPOSURE CONCENTRATIONS OF THE SAMPLING SITES IN YA'AN（mg/l）

\begin{tabular}{llcccccc}
\hline Serial Number & Sample Sites & $\mathrm{As}$ & $\mathrm{Hg}$ & $\mathrm{Cr}^{6+}$ & $\mathrm{Pb}$ & $\mathrm{Cd}$ & $\mathrm{F}$ \\
\hline 1 & Fuping village & 0.004 & 0.001 & 0.05 & 0.01 & 0.005 & 0.1 \\
2 & Liujia village & 0.004 & 0.001 & 0.05 & 0.01 & 0.005 & 1.4 \\
3 & Kanpo village & 0.004 & 0.001 & 0.05 & 0.01 & 0.005 & 0.1 \\
4 & Liuliang village & 0.004 & 0.001 & 0.015 & 0.01 & 0.005 & 0.39 \\
5 & Pingshi village & 0.004 & 0.001 & 0.005 & 0.01 & 0.005 & 0.32 \\
6 & Liba village & 0.004 & 0.001 & 0.006 & 0.01 & 0.005 & 0.12 \\
7 & Zhanggou village & 0.004 & 0.001 & 0.005 & 0.01 & 0.005 & 0.16 \\
8 & Baishu village & 0.004 & 0.001 & 0.005 & 0.01 & 0.005 & 0.36 \\
\hline
\end{tabular}

\section{B. Human Health Risk Calculation}

According to the health risk assessment model and the evaluation parameter, the average individual year risk created by the chemistry carcinogens and non-carcinogens through the drinking water in this district 2005 can be calculated. The results of calculation can be seen in chart 1. In research area, the highest average individual risk resulting from non-carcinogens is caused by fluoride, achieving $1.05 \times 10^{-8} / \mathrm{a}$.

The order of human health individual risk resulting from non-carcinogenicity toxic substances in research area is as follows: $\mathrm{Pd}>\mathrm{F}>\mathrm{Hg}$ and $\mathrm{Pb}$ accounts for $44.77 \%, \mathrm{~F}$ accounts for $34.30 \%, \mathrm{Hg}$ accounts for $20.92 \%$. The average individual year risk order of the 8 sampling points caused by the non-carcinogen is as follows: Number $2>$ Number $4>$ Number $8>$ Number $5>$ Number $7>$ Number $6>$ Number $3=$ Number 1 .

The average individual year risk caused by carcinogens can be seen in chart 2. Among the three kinds of carcinogens, average year risk of $\mathrm{Cr}^{6+}$ is the biggest, achieving $8.91 \times 10^{-4} / \mathrm{a}$. The order of health danger individual year risk resulting from carcinogenicity toxic substances in research area is as follows : $\mathrm{Cr}^{6+}>\mathrm{As}>\mathrm{Cd}$. $\mathrm{Cr}^{6+}$ accounts for $91.12 \%$, As accounts for $5.89 \%$, Cd accounts for $3.00 \%$. The order of the average individual year risk 
of the 8 sampling points caused by the carcinogen is as follows: Number $1=$ Number $2=$ Number $3>$
Number $4>$ Number $6>$ Number $5>$ Number $7=$ Number 8 .

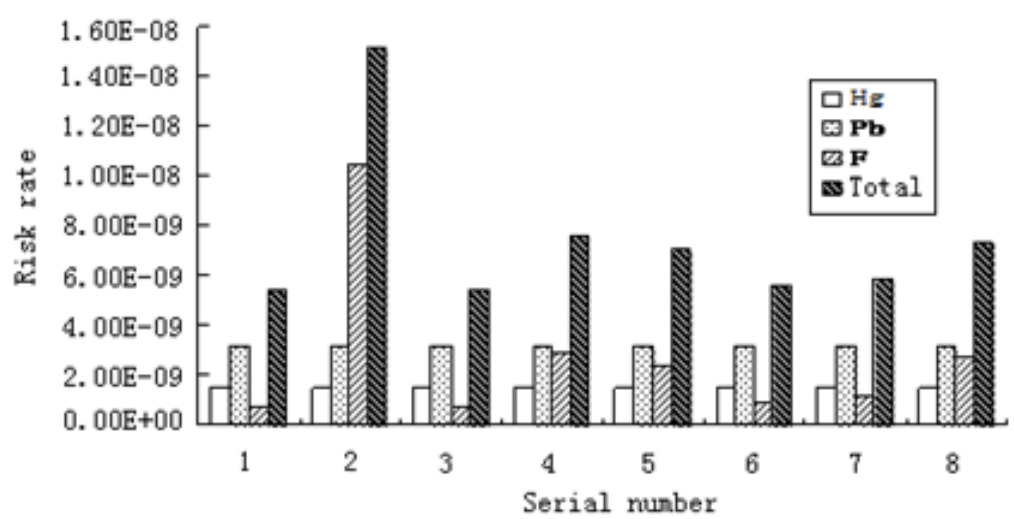

Chart 1. Average individual year risk caused by the chemical non-carcinogens substances

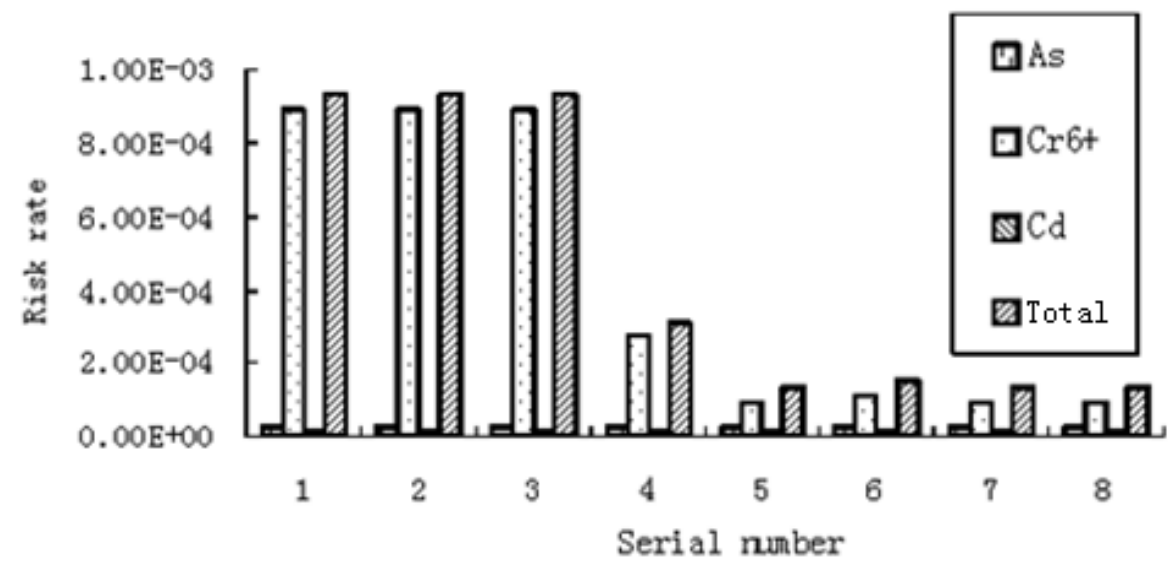

Chart. 2 Average individual year risk caused by the chemical caranogen substances

The level of human health danger individual year risk caused by non-carcinogens virulent chemical material concentrates in $10^{-8} \sim 10^{-10}$ /a. Namely, because of the drinking water's non-carcinogens pollutants, human health risk or the death population in each ten million people is less than one person .This indicates that the human health risk caused by the non-carcinogenicity chemical substances is slighter and will not be harmful to human health obviously. The level of human body health individual year risk caused by carcinogens virulent chemical substances concentrates in $10^{-4} \sim 10^{-5}$ /a. Namely, because of the drinking water's carcinogenic pollutants, the health dangers (or deaths) in each ten million are more than 100 or 1000 people.
Thus, the health danger individual year risk caused by carcinogenic toxic substances is much bigger than the health danger individual year risk caused by total non-carcinogen toxic substances in the research areas. The American Environmental Protection Bureau (EPA) carcinogenicity risk assessment guide pointed out that the risk was acceptable if the risk level was lower than $10^{-4} / \mathrm{a}$ in one year. The health danger individual year risk resulting from each kind of pollutant of rural drinking water source in Ya'an is in this level. But it surpasses the acceptable maximum $-5 \times 10^{-5} / \mathrm{a}$, which is recommended by International Commission on Radiological Protection (ICRP). 


\section{CONCLUSIONS AND SUGGESTIONS}

A. This study related the water environment quality to the hazard of public health, and described the degree of the hazard of public health caused by water environment pollution quantitatively. The research came to a comprehensive conclusion of water environment quality which was based on using health risk as index and made certain of the primary and secondary of water pollution and the priority of treatment, so that it provides a scientific basis and the decision-making object for the management of environmental risk.

B. The water environment health risks in Rain City District of Ya'an are mainly as follows: the pollution risk of urban water source; sudden water source pollution risk; the weak anti-risk ability caused by single water supply structure; sudden geological hazard will increase the risk of urban water supply system; water treatment and water supply risk; health risk of water source area in surrounding areas, etc. Through calculating, the biggest effects of the non-carcinogenic toxic substances on Ya'an drinking water source come from $\mathrm{Pb}$ and $\mathrm{F}$. But the health risk caused by the non-carcinogenic chemical substances is slight, and will not make the obvious harm to the human. The health danger individual year risk caused by carcinogenic toxic substances is much bigger than the one caused by non-carcinogens. The main pollutant is $\mathrm{Cr}^{6+}$, and its health risk is $10^{-4} / \mathrm{a}$, meeting the EPA requirements, but it is still higher than the maximal risk level that International Commission on Radiological Protection (ICRP) can accept.

Thus, $\mathrm{Cr}^{6+}, \mathrm{Pb}$ and $\mathrm{F}$ in water as the main control indexes of environment health risk should be used for the treatment in these water source areas; because the monitoring indexes exclude radioactive substance, the organic compounds are mainly figured by COD, BOD and the name and the level of each organic compound is not detected, the result is less than the practical one; this study is not took in details such as the exposure pathways beside drinking water and the sensitive degree of human individual characteristics to the pollutants in water. So there are still many aspects, for instance, the selection of data, the correction of models and parameters and the analysis of the effect of each toxicant's accumulation on human health, to be lucubrated.

C. The management of water environment health risk in Rain City District of Ya'an are mainly as follows: protecting water source, building water supply project, the water quality detection, the exploration and construction of emergency water source, the establishment of water safety emergency mechanism and effective implementation.

\section{REFERENCES}

[1] Fuquan Ni, Yuelin Yang, Huazhun Ren. Based on module type GIS technology rural drinking water security decision support system research [J]. Water scientific research, 2007.38-40. (In Chinese)

[2] Dakun Wang, etc. Application of health danger evaluation in environment quality evaluation [J]. Environmental pollution and prevention, 1995,7(5):91-92. (In Chinese)

[3] EPA. Superfund public health evaluation manual[R].EPA/540/186060.

[4] The US EPA. Available information on assessment exposure from pesticides in food U.S.Environmental Protection Agency Office of pesticides programs, June 21 , 2000.

[5] EPA. Supplement risk Assessment .Part 1[R].USA:EPA, 1989.26-35.

[6] Jijun Gao, Liping Zhang, ShenBiao Huang, etc. The heavy metal pollutant health risk preliminary appraisal of source of drinking water in Beijing [J].2004,25(2 ):47-50. (In Chinese)

[7] Guangming Zeng, Zuoli, Zhenglin Zhong. Water environment health risk evaluation model [J]. Water scientific advance, 1998,9(3):212-217.(In Chinese) 